\title{
GEOPROCESSAMENTO E SENSORIAMENTO REMOTO APLICADO NA DETERMINAÇÃO DA APTIDÃO AGRÍCOLA DE UMA MICROBACIA
}

\author{
Cláudia Webber Corseuil ${ }^{1}$; Sérgio Campos ${ }^{1}$; Fernanda Leite Ribeiro ${ }^{2}$; Teresa Cristina \\ Tarlé Pissarra $^{3}$; Flavia Mazzer Rodrigues ${ }^{3}$ \\ ${ }^{I}$ Departamento de Engenharia Rural, Faculdade de Ciências Agronômicas, Universidade Estadual Paulista, \\ Botucatu,SP, seca@fca.unesp.br \\ ${ }^{2}$ Departamento de Geociências, Universidade Estadual de Londrina, Londrina, $P R$ \\ ${ }^{3}$ Departamento de Engenharia Rural, Faculdade de Ciências Agrárias e Veterinária, Universidade Estadual \\ Paulista, Jaboticabal, SP
}

\section{RESUMO}

Atividades como agricultura e pecuária causam impactos significativos no meio ambiente, principalmente quando estas são praticadas de forma intensiva, desconsiderando a fragilidade e o potencial de uso dos recursos naturais. A análise de vários critérios ambientais como, aptidão agrícola do solo, área com necessidade de proteção, zoneamento ambiental, entre outros, permite realizar uma caracterização do meio físico, biótico e sócio-econôminco, voltada para a utilização racional dos recursos naturais. Desta forma, é essencial que se faça o planejamento das atividades a serem desenvolvidas numa área, considerando a aptidão dos recursos nela disponíveis. Para uma utilização racional desses recursos, é necessário considerar o seu potencial de uso. No caso específico dos solos, a interpretação dos levantamentos de solos é de grande importância, pois as características de cada unidade é que determina o seu potencial de uso. Assim, este estudo objetivou analisar as classes de aptidão agrícola das terras de uma bacia hidrográfica por meio de sistema de informação geográfica (SIG). A microbacia do Arroio Ajuricaba localiza-se no Município de Marechal Cândido Rondon-PR, entre as coordenadas UTM 787309m E e 793892m E; 7275026m N e $7281310 \mathrm{~m}$ $\mathrm{N}$, do Fuso 21, apresentando uma área de 1681ha. A base cartográfica digital utilizada foi o mapa de solos, em escala de semidetalhe. Os resultados permitiram concluir que $42,41 \%$ da bacia apresentam uma boa aptidão para lavouras no nível de manejo de alta tecnologia (nível de manejo C), regular para o B e restrita para o A [classe $1(\mathrm{a}) \mathrm{bC}$ ] e que $12 \%$ da área compreendem terras com aptidão regular para lavoura nos três níveis de manejo (classe 1abc). As terras da microbacia $(14,24 \%)$ apresentam uma aptidão regular para o uso com lavouras no nível de manejo $\mathrm{C}$, restrita para o B e inapta para o A [classe de aptidão 2(b)c]; 15,85\% apresentam aptidão boa para pastagem plantada (classe 4P) e 12,21\% são consideradas sem aptidão para uso agrícola (classe 6). Podemos dizer que $71,94 \%$ das terras possuem aptidão para lavouras, embora apresentem diferentes graus de limitações, que requerem tratamentos distintos para a sua conservação.

UNITERMOS: unidades de solo, aptidão agrícola, geoprocessamento.

\author{
CORSEUIL, C. W.; CAMPOS, S.; RIBEIRO, F. L.; PISSARRA, T. C. T.; \\ RODRIGUES, F. M.. GEOPROCESSING AND REMOTE SENSING APPLIED TO \\ DETERMINATION OF A WATERSHED AGRICULTURAL APTITUDE
}




\section{ABSTRACT}

Soil use for the development of activities as agriculture and livestock has been causing great alterations in the environment, mainly when these are practiced intensively, disrespecting the fragility and aptitude of the natural resources. Therefore, it is essential that the planning of the agricultural activities is done, taking into consideration the several environmental criteria involved in the decision-making process. Thus, this study aimed to analyze the agricultural aptitude classes of lands from a watershed through geographical information system (GIS). The Arroio Ajuricaba watershed is located in the Municipality of Marechal Cândido Rondon - PR among the coordinates UTM 787309m E and 793892m E; $7275026 \mathrm{~m} \mathrm{~N}$ and $7281310 \mathrm{~m} \mathrm{~N}$, in the Spindle 21, presenting an area of 1681ha. Soil maps, in semi detail scale, was the digital cartographic base used. The results allowed to conclude that $42.41 \%$ of the basin presented a good aptitude for farming in handling level of high technology (handling level C), regular aptitude for B, and restricted aptitude for A [class $1(\mathrm{a}) \mathrm{bC}]$ and that $12 \%$ of the area had regular aptitude for farming in the three handling levels (class labc). The watershed lands (14.24\%) presented regular aptitude for farming in handling level C, restricted aptitude for B, and inapt for A [class of aptitude 2(b)c]; $15.85 \%$ presented good aptitude for planted pasture (class 4P) and 12.21\% were considered without aptitude for agricultural use (class 6). We can say that $71.94 \%$ of the lands has aptitude for farming, although they present different degrees of limitations that request different treatments for its conservation.

KEY WORDS: soil units, agricultural aptitude, geoprocessing

\section{INTRODUÇÃO}

Atividades agrícolas, quando praticadas de forma intensiva, desconsiderando a fragilidade e o potencial de uso dos recursos naturais, causam impactos significativos no meio ambiente. Esses impactos podem ser exemplificados pela diminuição da qualidade e disponibilidade de água, pela estrutura e qualidade dos solos, refletindo no aporte de sedimentos, nutrientes, poluentes agroquímicos e dejetos de animais, ocasionando problemas de assoreamento e contaminação dos corpos d'água.

A análise de vários critérios ambientais como, aptidão agrícola das terras, áreas com necessidade de proteção, zoneamento ambiental, entre outros, permite a caracterização do meio físico, biótico e sócio-econômico, com vistas à utilização racional dos recursos naturais.

Desta forma, é essencial que se faça um planejamento das atividades a serem desenvolvidas numa determinada região, considerando o potencial de uso dos recursos naturais disponíveis.

No caso específico do solo, a sua interpretação constitui numa tarefa bastante relevante para a utilização racional na agricultura e em outros setores que utilizam este recurso como elemento integrante de suas atividades (Ramalho Filho \& Beek, 1995).

Essas interpretações, segundo os autores acima, podem ser realizadas para várias atividades agrícolas, classificando as terras de acordo com a sua aptidão para diversas culturas, considerando diferentes condições de manejo e viabilidade de melhoramento, por meio de novas tecnologias, necessidades de fertilizantes e corretivos, possibilitando a avaliação da demanda potencial de insumos em função da área cultivada. 
A avaliação das terras consiste no processo de estimar a sua aptidão, quando utilizada para fins específicos, envolvendo a execução e a interpretação de estudos sobre o solo, vegetação, clima, relevo entre outros aspectos, de modo a identificar e comparar os tipos de uso da terra mais adequados para uma determinada região.

Nascimento et al. (2004) comentam que a avaliação da aptidão das terras é importante e necessária, pois além de ser um instrumento imprescindível para a elaboração de zoneamentos, é um fator fundamental para estabelecer o uso dos recursos naturais segundo a aptidão, evitando, desta forma, a subutilização ou sobreutilização dos mesmos.

A sobreutilização, segundo os autores acima, caracteriza-se pelo uso das terras em atividades que vão além do seu potencial definido pelas limitações e que, após um determinado período, pode resultar em problemas ambientais. Nos dois casos, implicam em riscos para a manutenção da atividade exercida ao longo do tempo, caracterizando a falta de sustentabilidade.

$\mathrm{Na}$ área de estudo, atividades como a agricultura e a pecuária, muitas vezes, são realizadas em locais inadequados e nem sempre são utilizadas práticas conservacionistas. Observam-se áreas que deveriam ser destinadas à preservação permanente (como, matas ciliares e nascentes), sendo utilizadas para agricultura e pecuária, o que pode comprometer a produtividade e a sustentabilidade sócio-ambiental da comunidade.

Além disso, a microbacia está localizada nas proximidades do lago da Usina Hidrelétrica de ITAIPU - Binacional, da qual é contribuinte e atualmente enfrenta problemas de sedimentação e eutrofização da água devido a uma série de fatores, dentre os quais as atividades agrícolas desenvolvidas na área de entorno.

Desta forma, o estudo pode contribuir para o planejamento de atividades agrícolas desenvolvidas na microbacia, indicando as áreas com potencial ou limitação de uso.

Assim, este estudo teve por objetivo elaborar o mapa de classes de aptidão agrícola das terras e analisar a distribuição dessas classes por meio de técnicas de geoprocessamento, numa microbacia do município de Marechal Cândido Rondon-PR.

\section{MATERIAL E MÉTODOS}

O presente estudo foi realizado na bacia hidrográfica do Arroio Ajuricaba, localizada no município de Marechal Cândido Rondon, extremo oeste do Estado do Paraná.

A bacia ocupa uma área de 1.681 ha, correspondendo a $2,25 \%$ da área total do município (74.711,60 ha) e está situada entre as coordenadas $54^{\circ} 09^{\prime} 45^{\prime}$ ' WGr. e $54^{\circ} 05^{\prime} 55^{\prime \prime}$ WGr.; 24 $36^{\prime} 43^{\prime \prime} \mathrm{S}$ e $24^{\circ} 33^{\prime} 15^{\prime} \mathrm{S}$ (fuso $21 \mathrm{~S}$ e meridiano central $57^{\circ} \mathrm{W}$ ) (Figura 1).

O clima da região é do tipo subtropical úmido, mesotérmico, enquadrando-se de acordo com a classificação de Köppen no tipo $\mathrm{Cfa}$, com verões quentes, geadas pouco frequentes, tendências à concentração das chuvas nos meses de verão e sem estação seca definida. A temperatura média anual é de $21^{\circ} \mathrm{C}$, sendo que a média mínima é de $15^{\circ} \mathrm{C}$ e a média máxima é de $28^{\circ} \mathrm{C}$ (Iapar, 1978).

A precipitação anual é de $1.500 \mathrm{~mm}$, bem distribuídas o ano todo, sendo que no trimestre de verão (dezembro, janeiro e fevereiro) chega a $450 \mathrm{~mm}$ e no trimestre de inverno (junho, julho e agosto) atinge em torno de $250 \mathrm{~mm}$. A média anual da umidade relativa do ar fica em torno de $80 \%$ (Iapar, 1978). 


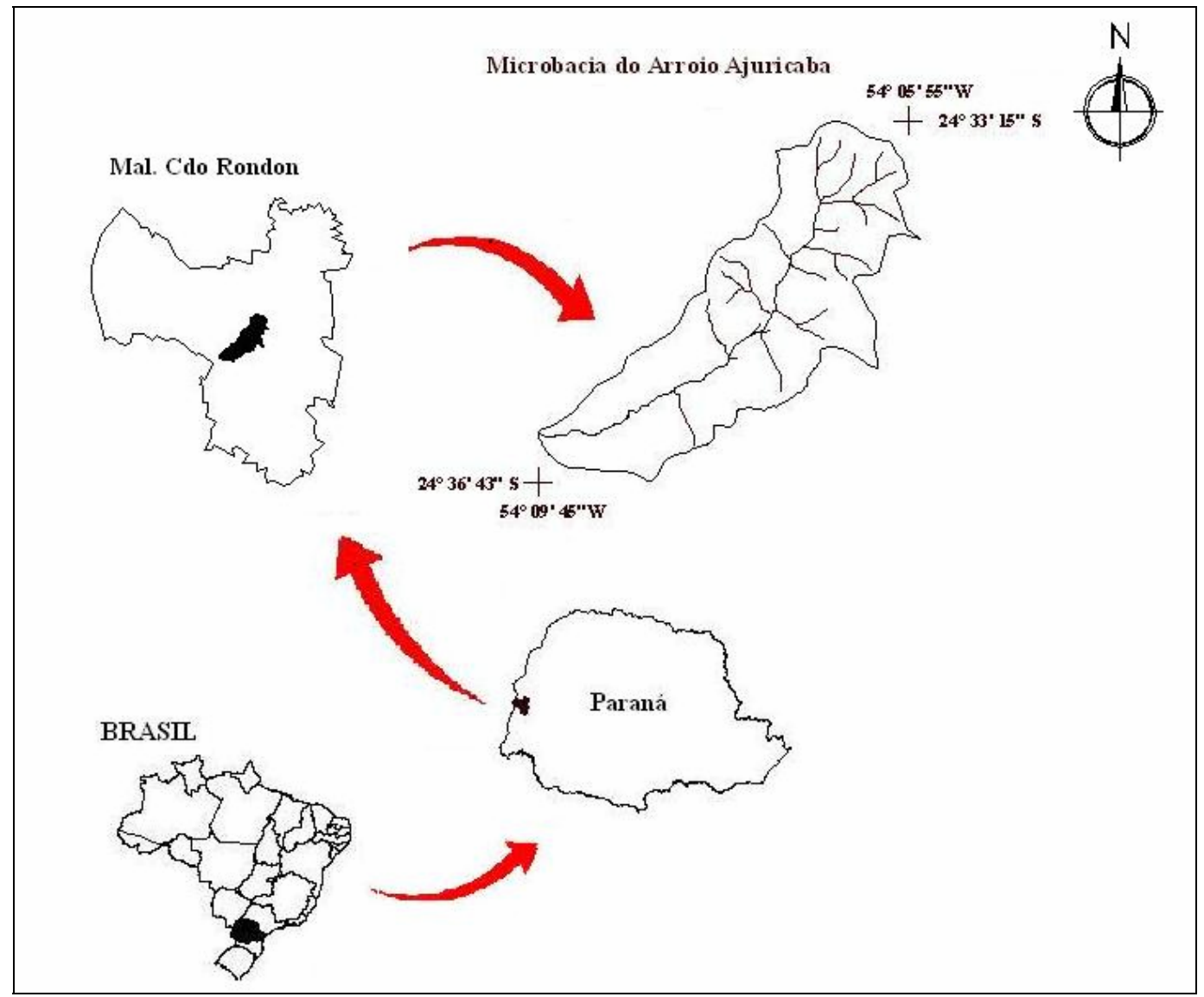

Figura 1. Localização da microbacia do Arroio Ajuricaba, Mal. Cândido Rondon - PR

O Estado do Paraná possui um relevo com formas de um extenso planalto, apresentando pequenas inclinações em direção ao noroeste, oeste e sudeste. As terras do Estado estão agrupadas em cinco unidades geomorfológicas que se sucedem de leste para oeste, que são: o litoral, a serra do mar, o primeiro planalto (ou de Curitiba), segundo planalto (ou de Ponta Grossa) e o terceiro planalto (ou de Guarapuava), conforme Maak (2002).

O município de Marechal Cândido Rondon situa-se na região do terceiro planalto, cujo relevo é constituído por patamares que se elevam gradativamente para leste, em colinas subtabulares modeladas em rochas básicas. A região apresenta um relevo predominantemente suave-ondulado (45\%), sendo o restante $15 \%$ plano, $30 \%$ ondulado e $10 \%$ forte ondulado (Marechal Cândido Rondon, 2005).

A vegetação nativa original era predominantemente de Floresta Estacional Semidecidual. Porém, devido à boa qualidade dos solos da região e a intensa expansão agrícola, a cobertura florestal original foi drasticamente substituída por lavouras e pastagens. Atualmente, as áreas de vegetação nativa ocorrem de forma isolada no interior das propriedades rurais e com poucas espécies características da floresta original, sendo que, grande parte são formações secundárias (Centro de Pesquisas Agropecuárias, 1993).

A hidrografia da região é constituída pelo rio Paraná e seus afluentes, dentre os quais se destaca o rio São Francisco Verdadeiro e o Arroio São Luiz. Parte dessa área, ao longo do Rio Paraná e seus afluentes, encontra-se recoberta pelo reservatório da usina hidrelétrica de Itaipu-Binacional (Centro de Pesquisa Agropecuária, 1993). 
Os tipos de solos dominantes da bacia de estudo, segundo levantamento realizado por Souza (2004) são: 1) CAMBISSOLO HÁPLICO Eutroférrico raso (CXef1); 2) CAMBISSOLO HÁPLICO Eutroférrico típico (CXef2); 3) ASSOCIAÇAO CAMBISSOLO HÁPLICO Eutroférrico típico + CAMBISSOLO HÁPLICO Eutroférrico raso (CXef3); NEOSSOLO FLÚVICO Eutrófico típico (RUe1); NEOSSOLO LITÓLICO Eutrófico gleico (RLe1); LATOSSOLO VERMELHO Eutroférrico câmbico (LVef1); NITOSSOLO VERMELHO Eutroférrico típico e latossólico (NVef1); NITOSSOLO VERMELHO Eutroférrico câmbico (NVef2); ASSOCIAÇÃO NITOSSOLO VERMELHO Eutroférrico câmbico + CAMBISSOLO HÁPLICO Eutroférrico típico.

Foram utilizados os seguintes materiais: a) base cartográfica digital, escala 1:50000, de Marechal Cândido Rondon-PR, folha SG-21-XB-VI-2, correspondente ao voo realizado em 1995 pela DSG (Diretoria do Serviço Geográfico), na projeção UTM, datum horizontal SAD-69 e vertical de Imbituba-SC; b) mapa de solos elaborado por Souza (2004), em escala 1:50.000, contendo as classes de solos no Sistema Brasileiro de Classificação de Solos (Embrapa, 1999); c) para a elaboração dos mapas e análise da distribuição espacial das classes de aptidão agrícola das terras da bacia utilizou-se o software Idrisi Kilimanjaro 14.0.

O mapa de aptidão agrícola das terras da microbacia foi obtido a partir da interpretação do levantamento pedológico da área, em nível de semidetalhe, realizado por Souza (2004), com base na metodologia de avaliação da aptidão agrícola das terras proposta por Ramalho Filho \& Beek (1995).

O sistema de avaliação da aptidão agrícola das terras consiste numa estimativa física das terras, baseada nas suas qualidades e em diferentes níveis de manejo. Esse sistema baseiase em levantamentos de solos e é realizado com o apoio de várias características físicoambientais da área, como: clima, vegetação, geomorfologia e unidades de solos (Ramalho Filho \& Beek, 1995).

O objetivo dessa classificação, de acordo com os autores acima, reside na orientação de como devem ser usados esses recursos no planejamento regional e nacional.

Sendo a classificação feita de forma interpretativa, ela possui um caráter efêmero e pode sofrer variações com a evolução tecnológica. Portanto, é dependente da tecnologia vigente na época de sua realização (Ramalho Filho \& Beek, 1995).

A estruturação básica desse método está descrita sucintamente a seguir:

a) Níveis de manejo (níveis de tecnologia): nesse sistema são considerados três níveis de manejo, indicados pelas letras $\mathrm{A}, \mathrm{B}$ e $\mathrm{C}$, as quais podem aparecer na simbologia da classificação escritas de formas diferentes, segundo as classes de aptidão que apresentem as terras, em cada um dos níveis adotados.

- Nível A (primitivo): baseado em práticas agrícolas que refletem um baixo nível técnicocultural. Quase não há aplicação de capital para o manejo, melhoramento e conservação das condições das terras e das lavouras. As atividades dependem basicamente de trabalho braçal, podendo ser usada a tração animal com implementos agrícolas simples.

- Nível B (pouco desenvolvido): reflete um nível tecnológico intermediário, com aplicação moderada de capital e utilização de resultados de pesquisas científica como dados para o manejo, melhoramento e conservação das condições das terras e das lavouras. A mecanização é baseada na tração animal ou motorizada e empregada para o desbravamento e preparo inicial do solo. As práticas agrícolas, neste nível de manejo, incluem calagem, adubação NPK, tratamento fitossanitário simples.

- Nível C (desenvolvido): baseado em práticas agrícolas que refletem um alto nível tecnológico, com aplicação intensiva de capital e utilização de resultados de pesquisas 
científica como dados para o manejo, melhoramento e conservação das condições das terras e das lavouras e o emprego de mecanização em quase todas as fases das atividades agrícolas.

Os níveis de manejo $\mathrm{B}$ e $\mathrm{C}$ envolvem melhoramentos tecnológicos em diferentes modalidades, entretanto, não consideram a irrigação na avaliação da aptidão agrícola das terras.

Quanto à pastagem plantada $(\mathrm{P})$ e à silvicultura (S), está prevista a aplicação moderada de fertilizantes, defensivos e corretivos, que corresponde ao nível de manejo B. No caso da pastagem natural $(\mathrm{N})$, está subentendida uma utilização sem melhoramentos tecnológicos, condição que caracteriza o nível de manejo A.

b) Grupos de aptidão

Os grupos de aptidão identificam o tipo de utilização mais intensivo das terras. $\mathrm{O}$ sistema apresenta seis grupos, numerados de 1 a 6 , em escala decrescente, de acordo o potencial de utilização das terras.

- Grupos 1, 2, e 3: são considerados próprios para lavouras;

- Grupo 4: próprios para pastagens cultivadas;

- Grupo 5: uso com pastagem natural e silvicultura;

- Grupo 6: considerado inapto para o uso agrícola, podendo ser destinados a preservação da flora e fauna.

c) Classes de aptidão

As classes expressam a aptidão agrícola das terras para um determinado tipo de utilização, com um nível de manejo definido, dentro do subgrupo de aptidão. Essas classes são definidas em termos de graus de intensidade, referentes aos fatores limitantes que afetam as terras, tais como: fertilidade natural, excesso de água, falta de água, susceptibilidade à erosão e impedimento à mecanização.

Esses fatores (também considerados como subclasse) definem as condições agrícolas das terras.

Os tipos de uso considerados são: lavouras, pastagem plantada, pastagem natural e silvicultura. As classes de aptidão estão classificadas em:

- Classe Boa - são terras sem limitações significativas para produção sustentável de um determinado tipo de utilização, considerando as condições de manejo. Esse fato permite inferir que existem restrições mínimas, porém elas não reduzem significativamente a produtividade ou os benefícios, bem como, não aumentam a quantidade de insumos acima de um nível aceitável.

- Classe Regular - são terras que apresentam limitações moderadas para a produção sustentável para um determinado tipo de uso da terra, observando as condições de manejo. As limitações reduzem a produtividade ou os benefícios, aumentando a necessidade de insumos para garantir as vantagens globais a serem obtidas com o uso.

- Classe Restrita - terras com limitações fortes para a produção sustentável de um determinado uso. As limitações reduzem os benefícios ou a produtividade, ou, então aumentam a quantidade de insumos necessários e, consequentemente, os custos.

- Classe Inapta - terras sem condições para uma produção sustentável do tipo de utilização considerada. A interpretação dessa classe é feita pela ausência de letras.

Para cada nível de manejo (A, B ou C) a aptidão da terra pode ser boa, representada pela letra maiúscula do respectivo manejo; regular, representada pela letra minúscula do 
respectivo manejo; restrita, representada pela letra minúscula entre parênteses; e, por fim, inapta, representada pela ausência de letras.

Para pastagem plantada, silvicultura e pastagem natural se aplicam a mesma simbologia, porém, utilizando-se as letras $\mathrm{P}, \mathrm{S}$, e N, respectivamente (Tabela 1).

Ramalho Filho \& Pereira (1999), analisando os principais métodos de avaliação de terras utilizados no Brasil, apontam que a avaliação das terras realizada por meio de um sistema de aptidão agrícola é bastante adequada para as características do país, uma vez que ele apresenta situações muito distintas em seu território, no que tange aos aspectos tecnológicos, científicos e culturais.

Além disso, os mesmos autores comentam que a prática de avaliação da aptidão agrícola de terras é fundamental, pois serve de subsídio para orientar o uso adequado das terras, evitando a subutilização dos recursos naturais.

Nascimento et al. (2004) descrevem que o requisito básico para a execução de sistemas racionais e sustentáveis de aproveitamento dos recursos naturais é a utilização da terra de acordo com a sua aptidão. Este procedimento baseia-se na avaliação de características específicas do solo e do ambiente, de acordo com o tipo de uso previsto. A sustentabilidade desses sistemas considera aspectos econômicos, sociais e ambientais, sendo muitas vezes relacionados entre si. $\mathrm{O}$ aspecto ambiental envolve diretamente a utilização dos recursos naturais (em especial o solo e a água), a disponibilidade destes em condições adequadas e a manutenção da diversidade e do potencial genético das espécies vegetais e animais visando a sua preservação.

Tabela 1. Simbologia das classes de aptidão agrícola das terras

\begin{tabular}{|c|c|c|c|c|c|}
\hline \multirow{3}{*}{ Aptidão Agrícola } & \multicolumn{5}{|c|}{ TIPO DE UTILIZAÇÃO } \\
\hline & \multicolumn{2}{|l|}{ Lavouras } & $\begin{array}{l}\text { Pastagem } \\
\text { Plantada }\end{array}$ & Silvicultura & Pastagem \\
\hline & \multicolumn{5}{|c|}{ Nível de manejo } \\
\hline Boa & A & $\mathrm{C}$ & $\mathrm{P}$ & $\mathrm{S}$ & $\mathrm{N}$ \\
\hline Regular & $\mathrm{b}$ & $\mathrm{c}$ & $\mathrm{P}$ & $\mathrm{S}$ & $\mathrm{N}$ \\
\hline Restrita & (a) (b) & (c) & (p) & $(\mathrm{s})$ & (n) \\
\hline Inapta & - & - & - & - & - \\
\hline
\end{tabular}

Fonte: adaptada de Ramalho Filho \& Beek (1995).

\section{RESULTADOS E DISCUSSÃO}

O solo mais representativo da bacia (Figura 1 e Tabela 2), é o NITOSSOLO VERMELHO Eutroférrico típico e Latossólico (NVefl) com 712,95ha, correspondendo a $42,4 \%$ da área total.

As classes de aptidão agrícola (Figura 2 e Tabela 2) determinadas a partir do levantamento dos solos e com base na metodologia de avaliação das terras de Ramalho Filho \& Beek (1995) permitiram inferir que a classe de aptidão agrícola 1(a)Bc foi a mais significativa, pois abrange mais de $40 \%$ da área da bacia. Essas terras são apropriadas para o cultivo com lavouras no nível de manejo $\mathrm{C}$, pois apresentam classe de aptidão boa. Esses dados permitem inferir que as terras da bacia vêm sendo ocupadas adequadamente, pois essas 
áreas apresentam grande potencial para o cultivo com culturas agrícolas, ou seja, uso intensivo.
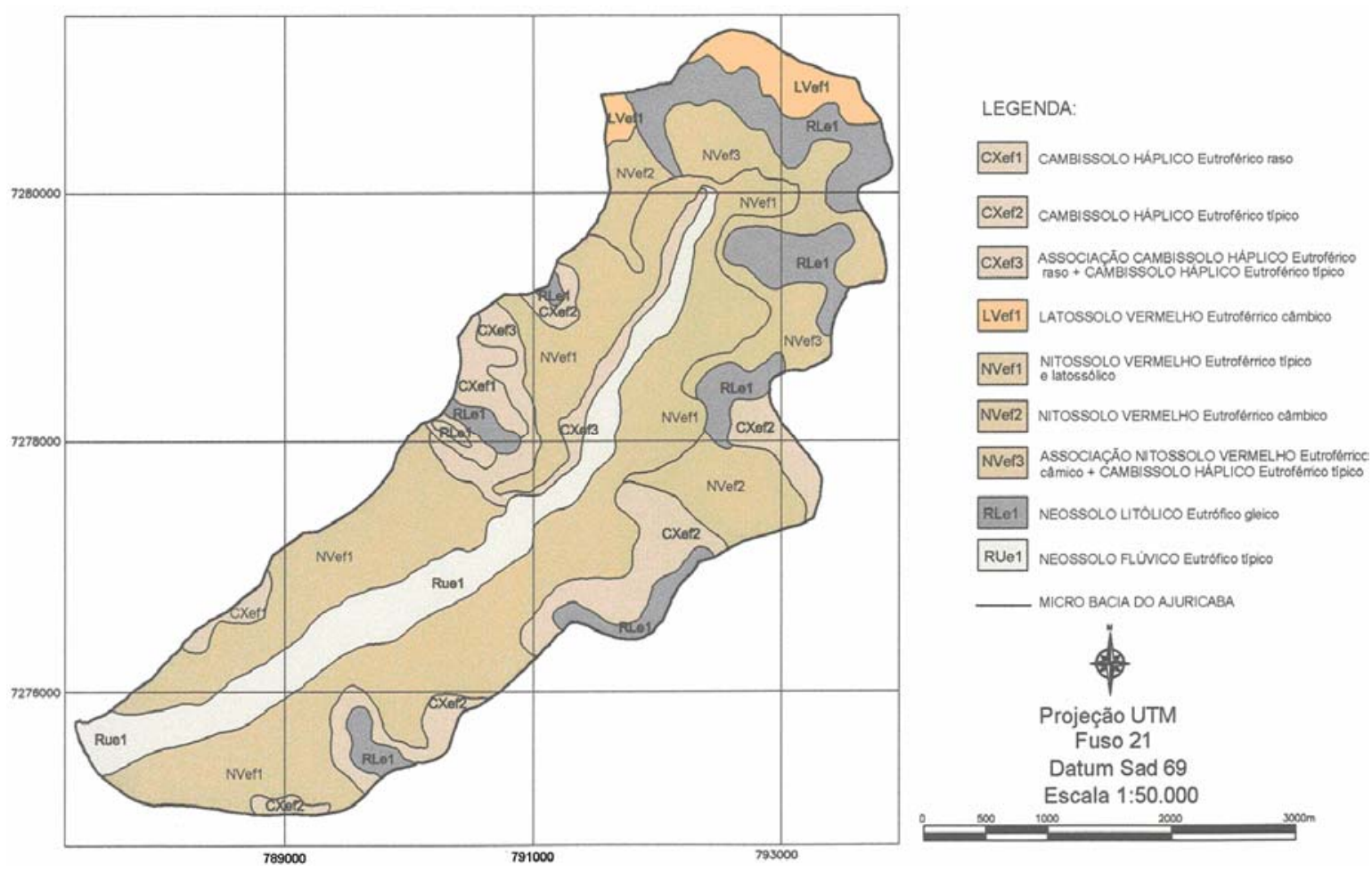

Figura 1. Mapa de solos ocorrentes na microbacia do Arroio Ajuricaba - Marechal Cândido Rondon (PR), segundo Souza (2004).

Tabela 2. Unidades de solos ocorrentes na microbacia do Arroio Ajuricaba - Marechal Cândido Rondon (PR), segundo Souza (2004).

\begin{tabular}{l|l|l|l}
\hline \multirow{2}{*}{ Legenda } & \multirow{2}{*}{ Classes de solos } & \multicolumn{2}{l}{ Área } \\
\cline { 3 - 4 } & & ha & $\%$ \\
\hline CXef1 & CAMBISSOLO HÁPLICO Eutroférrico raso & 47,61 & 2,8 \\
\hline CXef2 & CAMBISSOLO HÁPLICO Eutroférrico típico & 149,50 & 9,0 \\
\hline CXef3 & $\begin{array}{l}\text { ASSOCIAÇÃO CAMBISSOLO HÁPLICO Eutroférrico } \\
\text { típico + CAMBISSOLO HÁPLICO Eutroférrico raso }\end{array}$ & 69,30 & 4,1 \\
\hline LVef1 & LATOSSOLO VERMELHO Eutroférrico câmbico & 56,00 & 3,3 \\
\hline NVef1 & NITOSSOLO VERMELHO Eutroférrico típico e latossólico & 712,95 & 42,4 \\
\hline NVef2 & NITOSSOLO VERMELHO Eutroférrico câmbico & 101,10 & 6,0 \\
\hline NVef3 & $\begin{array}{l}\text { ASSOCIAÇÃO NITOSSOLO VERMELHO Eutroférrico } \\
\text { câmbico CAMBISSOLO HÁPLICO Eutroférrico típico }\end{array}$ & 138,24 & 8,2 \\
\hline RLe1 & NEOSSOLO LITÓLICO Eutrófico gleico & 205,20 & 12,2 \\
\hline RUe1 & NEOSSOLO FLÚVICO Eutrófico típico & 201,10 & 12,0 \\
\hline TOTAL & & $1.681,00$ & 100,00 \\
\hline
\end{tabular}


As classes de aptidão agrícola (Figura 2 e Tabela 2) determinadas a partir do levantamento dos solos e com base na metodologia de avaliação das terras de Ramalho Filho \& Beek (1995) permitiram inferir que a classe de aptidão agrícola 1(a)Bc foi a mais significativa, pois abrange mais de $40 \%$ da área da bacia. Essas terras são apropriadas para o cultivo com lavouras no nível de manejo $\mathrm{C}$, pois apresentam classe de aptidão boa. Esses dados permitem inferir que as terras da bacia vêm sendo ocupadas adequadamente, pois essas áreas apresentam grande potencial para o cultivo com culturas agrícolas, ou seja uso intensivo.

Os dados evidenciam também que $42,41 \%$ da área apresentam uma boa aptidão para lavouras no nível de manejo de alta tecnologia (nível de manejo $\mathrm{C}$ ), regular para o $\mathrm{B}$ e restrita para o A [classe 1(a)bC]. Essas terras encontram-se distribuídas ao longo de toda microbacia. Aproximadamente, $12 \%$ da área compreendem as terras que apresentam uma aptidão regular para lavoura nos três níveis de manejo (classe 1abc). As terras pertencentes a essa classe de aptidão estão localizadas nas baixadas, próximas aos cursos de água.

Pela Figura 2 e Tabela 3 verifica-se que as melhores terras para a exploração agrícola, nos três níveis de manejo (Classe $1 \mathrm{ABC}$ ), ocupam apenas 3,33\% da área total e estão localizadas mais na porção norte da microbacia.

Ainda, 14,24\% das terras da microbacia apresentam uma aptidão regular para o uso com lavouras no nível de manejo $\mathrm{C}$, restrita para o $\mathrm{B}$ e inapta para o $\mathrm{A}$ [classe de aptidão 2(b)c]; $15,85 \%$ apresentam aptidão boa para pastagem plantada (classe 4P) e 12,21\% são consideradas sem aptidão para uso agrícola (classe 6).

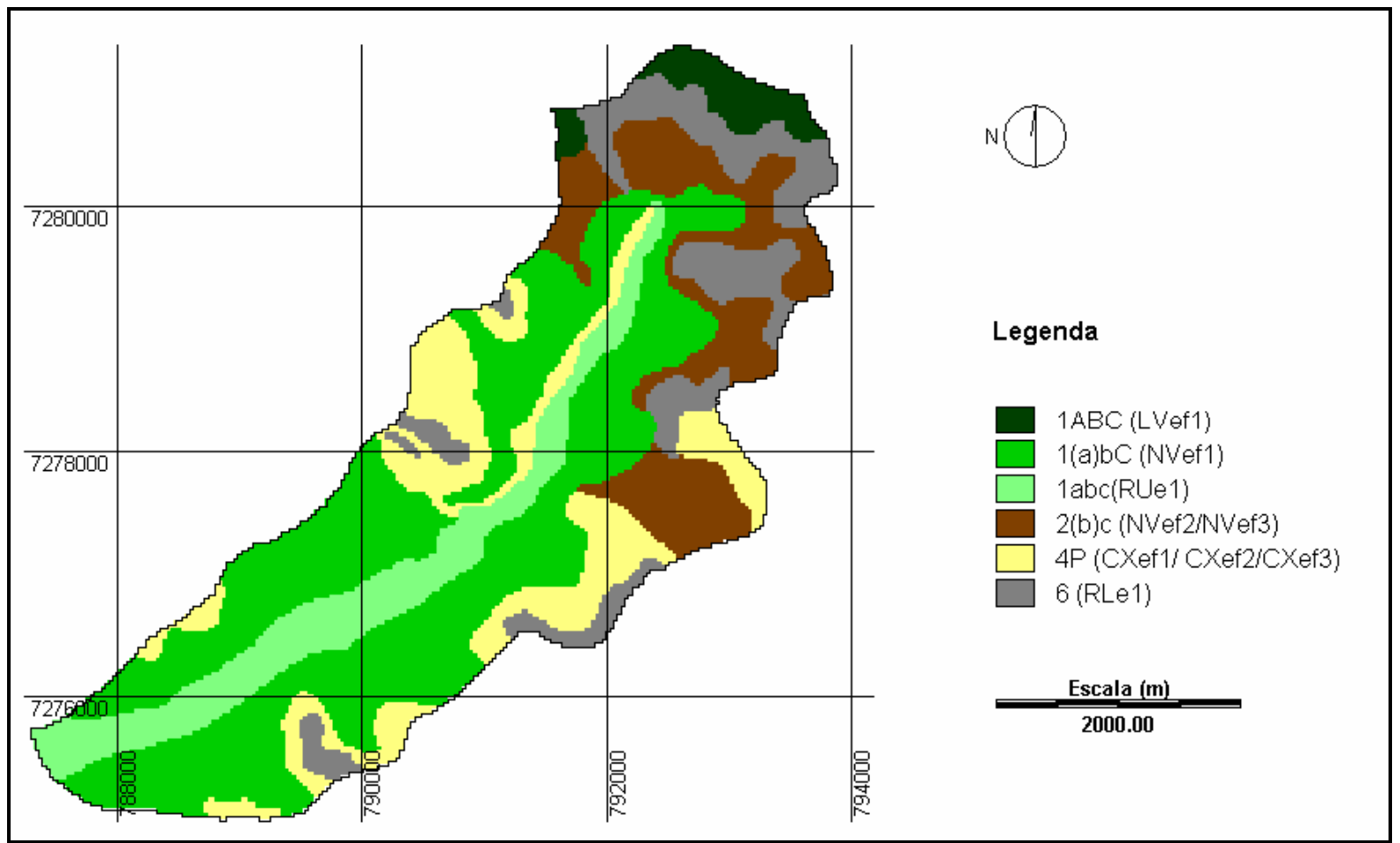

Figura 2. Mapa de aptidão agrícola das terras da microbacia do Arroio Ajuricaba - Marechal Cândido Rondon (PR).

Numa análise mais generalizada, percebe-se que $71,94 \%$ das terras possuem aptidão para lavouras, embora apresentem diferentes graus de limitações que requerem tratamentos distintos para a sua conservação. 
O Sistema de Informação Geográfica - Idrisi mostrou-se eficiente na determinação das classes de aptidão agrícola da microbacia, demonstrando que a utilização de técnicas de geoprocessamento facilita e agiliza o cruzamento de dados, permitindo o armazenamento digital de dados que poderão ser utilizados para outras análises, sobretudo para futuros planejamentos territorial e ambiental da área (Eastman, 2003).

Tabela 3. Classes de aptidão agrícola das terras da microbacia do Arroio Ajuricaba - Marechal Cândido Rondon (PR).

\begin{tabular}{l|l|l|l}
\hline \multicolumn{1}{l|}{ Classes de aptidão agrícola } & \multicolumn{2}{l}{ Área } \\
\hline Simbologia & Descrição & ha & $\%$ \\
\hline 1 ABC & $\begin{array}{l}\text { Terras pertencentes à classe de aptidão boa para lavouras nos } \\
\text { níveis de manejo A, B e C. }\end{array}$ & 56,0 & 3,33 \\
\hline $1(\mathrm{a}) \mathrm{Bc}$ & $\begin{array}{l}\text { Terras pertencentes à classe de aptidão boa para lavouras no } \\
\text { nível de manejo C, regular no B e restrita no A. }\end{array}$ & 713,00 & 42,41 \\
\hline 1 abc & $\begin{array}{l}\text { Terras pertencentes à classe de aptidão regular para lavouras } \\
\text { nos níveis de manejo A, B e C. }\end{array}$ & 201,10 & 11,96 \\
\hline $2(b) c$ & $\begin{array}{l}\text { Terras pertencentes à classe de aptidão regular para lavouras } \\
\text { no nível de manejo C, restrita no B e inapta no A. }\end{array}$ & 239,30 & 14,24 \\
\hline $4 P$ & $\begin{array}{l}\text { Terras pertencentes à classe de aptidão boa para Pastagem } \\
\text { Plantada. }\end{array}$ & 266,40 & 15,85 \\
\hline 6 & Terras sem aptidão para uso agrícola. & 205,20 & 12,21 \\
\hline
\end{tabular}

\section{CONCLUSÕES}

Os resultados permitiram concluir que mais $2 / 5$ da bacia apresentam uma boa aptidão para lavouras no nível de manejo de alta tecnologia (nível de manejo $\mathrm{C}$ ), regular para o $\mathrm{B}$ e restrita para o A [classe $1(\mathrm{a}) \mathrm{bC}$ ] e que $12 \%$ da área compreendem as terras com aptidão regular para lavoura nos três níveis de manejo (classe labc). As terras da microbacia $(14,24 \%)$ apresentam uma aptidão regular para o uso com lavouras no nível de manejo $\mathrm{C}$, restrita para o B e inapta para o A [classe de aptidão 2(b)c]; 15,85\% apresentam aptidão boa para pastagem plantada (classe 4P) e 12,21\% são consideradas sem aptidão para uso agrícola (classe 6).

Podemos dizer que mais de $70 \%$ das terras possuem aptidão para lavouras, embora apresentem diferentes graus de limitações que requerem tratamentos distintos para a sua conservação. 


\section{REFERÊNCIAS BIBLIOGRÁFICAS}

MARECHAL CÂNDIDO RONDON (Município). Centro de Pesquisas Agropecuárias, 1993. p.

EASTMAN, J. R. Idrisi Kilimanjaro: Guide to GIS and Image Processing. Worcester: Clark University, 2003. 328p. Manual Version 14.00.

EMBRAPA. Sistema brasileiro de classificação de solos. Centro Nacional de Pesquisas de Solos.. Rio de Janeiro (RJ), 1999. 412p.

FAO. A framework for land evaluation. Soils bulletin 3. FAO And Agriculture Organization Of The United Nations, Rome. 1976.

FUNDAÇÃO INSTITUTO AGRONÔMICO DO PARANÁ. Cartas Climáticas Básicas do Estado do Paraná. Londrina, PR, 1978.

MAAK, R. Geografia física do Estado do Paraná. Curitiba: Imprensa Oficial, 2002. 440p. MARECHAL CÂNDIDO RONDON. Disponível em: $<$ http://pt.wikipedia.org/wiki/Marechal_C\%C3\%A2ndido_Rondon $>$ Acesso em outubro de 2005.

NASCIMENTO, P. C., GIASSON, E., INDA Jr., A V. Aptidão de uso dos solos e meio ambiente. In: AZEVEDO, A. C., DALMOLIN, R. S. D., PEDRON, F. A. (Editores). Solos \& ambiente: I fórum Solos \& ambiente. Santa Maria: Pallotti, 2004. p. 41-57.

OLIVEIRA, J.B. DE; CAMARGO, M.N.; ROSSI, M.; CALDERAN FILHO. Mapa pedológico do Estado de São Paulo: Legenda expandida. EMBRAPA. Campinas: 1999. 64p.

RAMALHO FILHO, A.; BEEK, K. L. Sistema de avaliação da aptidão agrícola das terras. $3^{\text {a }}$ ed ver. - Rio de Janeiro: EMBRAPA - CNPS, 1995. 65p.

RAMALHO FILHO, A.; PEREIRA, L. C. Aptidão agrícola das terras do Brasil: potencial de terras e análise dos principais métodos de avaliação. Rio de Janeiro: EMBRAPA - SOLOS, 1999. 36p.

RODERJAN, C. V. et al. As unidades fitogeográficas do Estado do Paraná. Revista Ciência \& ambiente, Santa Maria: UFSM, v.1, n. 24, p.75-92, Jan./Jun. 2002.

SOUZA, M. L. P. Levantamento de solos e do risco ambiental das terras da sub bacia do Córrego Ajuricaba, município de Marechal Cândido Rondon-PR. Programa Cultivando Água Boa _ ITAIPU. TERRA-Planejamento Ambiental Consultoria Agronômica. Curitiba - PR, 2004. 